\title{
New Approach for the Construction and Calibration of Gas-Tight Setups for Biohydrogen Production at the Small Laboratory Scale
}

\author{
Caroline Autenrieth ${ }^{1, *} \mathbb{D}$, Shreya Shaw ${ }^{1,2}$ and Robin Ghosh ${ }^{1}$ (D) \\ 1 Institute of Biomaterials and Biomolecular Systems, Department of Bioenergetics, University of Stuttgart, \\ Pfaffenwaldring 57, D-70569 Stuttgart, Germany; Shreya.Arun.Shaw@asu.edu (S.S.); \\ robin.ghosh@bio.uni-stuttgart.de (R.G.) \\ 2 School of Molecular Sciences, Tempe Campus, Mailcode 1604, Arizona State University, \\ Tempe, AZ 85281, USA \\ * Correspondence: caroline.autenrieth@bio.uni-stuttgart.de; Tel.: +49-711-685-65048
}

Citation: Autenrieth, C.; Shaw, S.; Ghosh, R. New Approach for the Construction and Calibration of Gas-Tight Setups for Biohydrogen Production at the Small Laboratory Scale. Metabolites 2021, 11, 667 . https://doi.org/10.3390/ metabo11100667

Academic Editor: Silas G. Villas-Boas

Received: 4 August 2021

Accepted: 25 September 2021

Published: 29 September 2021

Publisher's Note: MDPI stays neutral with regard to jurisdictional claims in published maps and institutional affiliations.

Copyright: (c) 2021 by the authors. Licensee MDPI, Basel, Switzerland. This article is an open access article distributed under the terms and conditions of the Creative Commons Attribution (CC BY) license (https:/ / creativecommons.org/licenses/by/ $4.0 /)$.

\begin{abstract}
Biohydrogen production in small laboratory scale culture vessels is often difficult to perform and quantitate. One problem is that commonly used silicon tubing and improvised plastic connections used for constructing apparatus are cheap and easy to connect but are generally not robust for gases such as hydrogen. In addition, this type of apparatus presents significant safety concerns. Here, we demonstrate the construction of hydrogen-tight apparatus using a commercially available modular system, where plastic tubing and connections are made of explosion-proof dissipative plastic material. Using this system, we introduce a gas chromatograph calibration procedure, which can be easily performed without necessarily resorting to expensive commercial gas standards for the calibration of hydrogen gas concentrations. In this procedure, the amount of hydrogen produced by the reaction of sodium borohydride with water in a closed air-filled bottle is deduced from the observed decrease of the oxygen partial pressure, using the ideal gas law. Finally, the determined calibration coefficients and the gas-tight apparatus are used for the analysis of simultaneous oxygen consumption and hydrogen production of the purple photosynthetic bacterium, Rhodospirillum rubrum, during semiaerobic growth in the dark.
\end{abstract}

Keywords: biohydrogen; purple bacteria; Rhodospirillum rubrum; dark photosynthesis; gas chromatography; calibration; $\mathrm{H}_{2}$-technology

\section{Introduction}

Many cellular metabolic processes are intrinsically associated with gas production or consumption. The construction of a gas-tight apparatus for hydrogen production and measurement is not a challenge in an engineering environment. However, in the area of biohydrogen (bio- $\mathrm{H}_{2}$ ) production by algae, cyanobacteria and purple bacteria (for relevant reviews see [1-5]), the initial process development strategy is usually performed at the small laboratory scale [6-12], and many of the current developments are being undertaken by biologists, who often have little or no formal training in engineering, and are often stymied by the technical requirements for gas production and collection. Typically, training in the construction of tubed apparatus in a biochemical laboratory usually involves improvised connections between silicon tubing (which is prone to sparking due to static charging) and PTFE or silicon plugs, or to glass tubing. This type of apparatus (such as that described in a recent protocol [13]) is cheap, delivers results, but is not really hydrogen gas-tight, and presents significant safety concerns. In particular, the so-called EX-protection (i.e., the apparative measures necessary for preventing explosions and for protecting experimentalists against explosions) can only be achieved when the experimental setup is placed into an explosion proof hood. The technical alternative to silicone tubing, tailor-made all-metal 
connections are not only expensive, but are also difficult to construct without training in engineering or access to the appropriate tools.

One aspect of the present work is to demonstrate that a recently introduced modular EX-protected (the plastic material has been rendered highly conductive $\left(1000 \mathrm{kOhm} \mathrm{m}^{-1} \cdot \mathrm{m}^{-1}\right)$ by mixing with conductive graphite) construction system, originally conceived for chemical engineering applications, which is also extremely gas-tight to $\mathrm{H}_{2}$, can be easily modified for biological applications where the measurement of metabolic gases is an issue. The gas tight-assembly setups built with this material can be used outside a protective hood, which facilitates the use with larger volumes, commonly employed in growth experiments, and provides a straightforward path to up-scaling in an engineering environment.

For the accurate measurement of bio- $\mathrm{H}_{2}$, gas chromatography (GC) is the method of choice (see [14] for an extensive comparison of different methods for measurements of bio- $\mathrm{H}_{2}$ production. We note that the methods we present below are complimentary to those described in [14]). However, a significant problem for biologists in the bio- $\mathrm{H}_{2}$ area is the calibration of the GC for the measurement of gas production in closed vessels, such as bottles or shake flasks, commonly used for hydrogen production at the small laboratory scale. The problem here is that bio- $\mathrm{H}_{2}$ production from a microorganism in a closed bottle, almost inevitably leads to an increase in total pressure within the headspace to be sampled, which, without appropriate correction, can lead to significant errors when the gas composition is monitored by GC. In the method we present here, however, our closed, gas-tight, EX-protected setup uses a large gas reservoir to keep the total pressure nearly constant. Gas samples are measured with a GC, which has been calibrated beforehand using a simple calibration method (using only GC raw data and a knowledge of the gas laws), which is also described in the first part of our study. This method is now suitable for measurements of semi-aerobic growth regimes, where the consumption of $\mathrm{O}_{2}$ and the production of $\mathrm{CO}_{2}$ and $\mathrm{H}_{2}$ occur simultaneously, which is not measurable using the water displacement method [13], since an observed pressure change is not linear with the level of $\mathrm{H}_{2}$ production. Our method can easily be extended to samples of non-atmospheric pressure provided that gas dilution prior to measurement is performed (see below).

Finally, we present an application of our protocol, by analysing the gas $\left(\mathrm{O}_{2}, \mathrm{H}_{2}\right.$ and $\mathrm{CO}_{2}$ ) uptake and production of the purple non-sulphur bacterium Rhodospirillum rubrum, grown using a high cell density medium that also induces the photosynthetic genes (including some responsible for $\mathrm{H}_{2}$ production) maximally under the dark conditions [15].

\section{Results}

2.1. Calculation of the Conversion Coefficients for the Determination of the Concentrations of $\mathrm{O}_{2}$, $\mathrm{H}_{2}$ and $\mathrm{CO}_{2}$ Directly from the GC Peak Area

A typical GC-profile of a $\mathrm{H}_{2}$-containing gas sample is shown below (Figure 1). The assignment of peaks was performed as described in Section 4.

The conversion of the peak signal area (in $\mathrm{mV} \cdot \mathrm{min}$ ) into an absolute gas concentration can be demanding. One possibility is to employ a reference sample with a defined gas mixture of known concentrations, usually obtained from a gas cylinder. However, in this case, the experimental difficulty is to correct for the higher pressure in the gas cylinder, which is released in the sample measuring loop. In addition, this method generally requires the availability of commercial gas mixtures, which can be costly to maintain. In this work, we demonstrate an alternative method, whereby, using only ambient air and a simple $\mathrm{H}_{2}$-generating system, the absolute concentrations of $\mathrm{O}_{2}, \mathrm{H}_{2}$, and $\mathrm{CO}_{2}$ can be determined directly from the GC profile by a straightforward application of the ideal gas equation. 


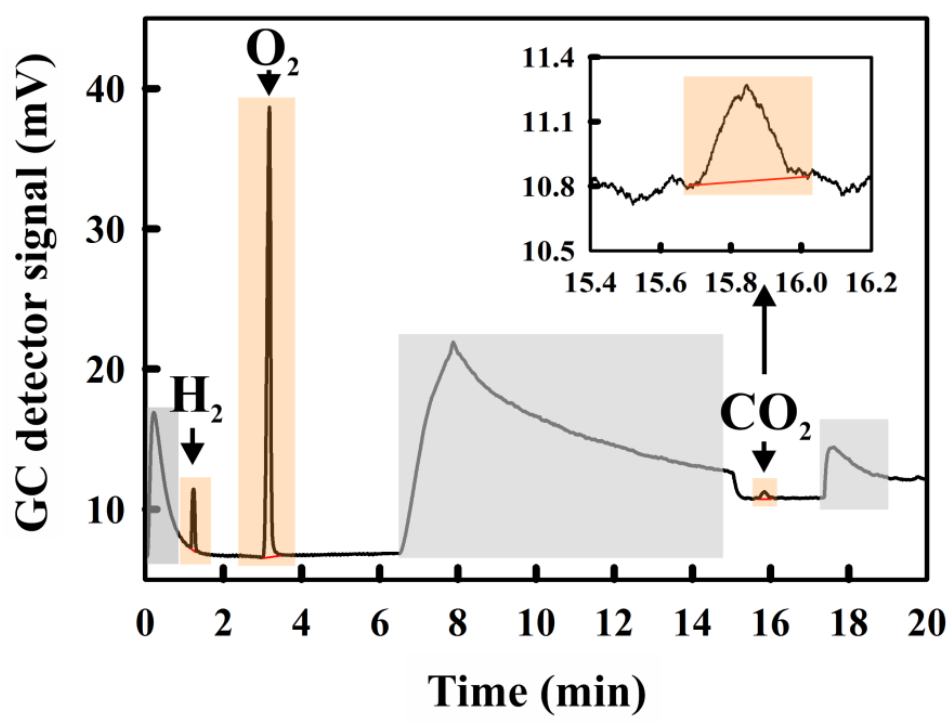

Figure 1. Gas chromatography chromatogram for a gas sample containing $\mathrm{H}_{2}, \mathrm{O}_{2}$, and $\mathrm{CO}_{2}$ (orange shaded regions), respectively. Inset: expanded view of the $\mathrm{CO}_{2}$ peak; grey shaded regions: the background output due to the injection artefact ( $0-1 \mathrm{~min}$ ) due to transient mixing of the $\mathrm{N}_{2}$ carrier gas with the sample, the temperature ramp (start at $6.5 \mathrm{~min})$, and residual dirt in the column (17 $\mathrm{min})$.

\subsubsection{The Reference Value: The GC-Conversion Coefficient for $\mathrm{O}_{2}$}

For determination of the $\mathrm{O}_{2}$ conversion coefficient, ambient air samples were used. Atmospheric air has a near-constant gas composition and contains $78.10 \mathrm{~mol} \% \mathrm{~N}_{2}$, $20.95 \mathrm{~mol} \% \mathrm{O}_{2}$, small amounts of argon (approx. $0.9 \mathrm{~mol} \%$ ) and other (noble) gases, and $0.03-0.05 \mathrm{~mol} \% \mathrm{CO}_{2}$. Thus, the GC-peak area obtained for $\mathrm{O}_{2}$ can be converted directly into the molar $\mathrm{O}_{2}$ concentration by applying the ideal gas equation:

$$
P_{\mathrm{O}_{2}} V_{L}=n_{\mathrm{O}_{2}} R T
$$

where $\mathrm{P}_{\mathrm{O} 2}$ is the partial pressure of $\mathrm{O}_{2}, \mathrm{~V}_{\mathrm{L}}$ is the volume of the sample loop $(1 \mathrm{~mL}), \mathrm{n}_{\mathrm{O} 2}$ is the molar number of $\mathrm{O}_{2}$ in the sample, $\mathrm{R}$ is the gas constant $\left(8.314 \mathrm{~J} \cdot \mathrm{mol}^{-1} \cdot \mathrm{K}^{-1}\right)$ and $\mathrm{T}$ is the absolute temperature of the sample.

To obtain a reliable value for this coefficient, a total of $22 \mathrm{O}_{2}$ peak area (PA) measurements were performed over a period of 4 days. For each measurement, the ambient temperature $\left(20.0-21.3^{\circ} \mathrm{C}\right)$ was measured with a digital thermocouple and the atmospheric pressure $(0.0993-0.1037 \mathrm{MPa})$ was obtained from the online campus weather station.

From these measurements we calculated the $\mathrm{O}_{2}$ conversion coefficient:

\section{$\mathrm{O}_{2}$ conversion coefficient $=\underline{2.417} \mu \mathrm{mol} \mathrm{O} 2 / \mathrm{mV} \cdot \mathbf{m i n}$.}

The standard deviation was $0.054 \mu \mathrm{mol} / \mathrm{mV} \cdot \mathrm{min}$, i.e., a $2.2 \%$ error.

\subsubsection{Determination of the GC-Conversion Coefficient for $\mathrm{H}_{2}$}

We have employed the well-known hydrolysis of sodium borohydride $\left(\mathrm{NaBH}_{4}\right)$ to generate defined amounts of $\mathrm{H}_{2}$ in a closed system. The stoichiometry of the reaction (in the presence of excess $\mathrm{H}_{2} \mathrm{O}$ ) is given by Equation (2):

$$
\mathrm{NaBH}_{4}+2 \mathrm{H}_{2} \mathrm{O} \Rightarrow \mathrm{NaBO}_{2}+4 \mathrm{H}_{2}
$$

Note that, for clarity, we only show the major reaction of $\mathrm{NaBH}_{4}$ with excess $\mathrm{H}_{2} \mathrm{O}$ here. The hydrolysis of $\mathrm{NaBH}_{4}$ has been considered in detail elsewhere [16,17]. 
The $\mathrm{H}_{2}$-producing reaction was performed in a 1 litre bottle, which was closed with a home-made gas-tight cap assembly incorporating a septum for gas sampling. We used connections and tubings made of a special conductive plastic material. This material is particularly advantageous for small-scale laboratory setups in that the parts made from it are not only designed to be $\mathrm{H}_{2}$-tight but also incorporate chemically inert but conductive material which dissipates static charge, thereby mitigating the danger of explosion. Figure 2 shows our experimental gas-tight setup for $\mathrm{H}_{2}$ production in a closed bottle. More details can be found in Section 4 and in Supplementary Figure S1 and Supplementary Table S1.

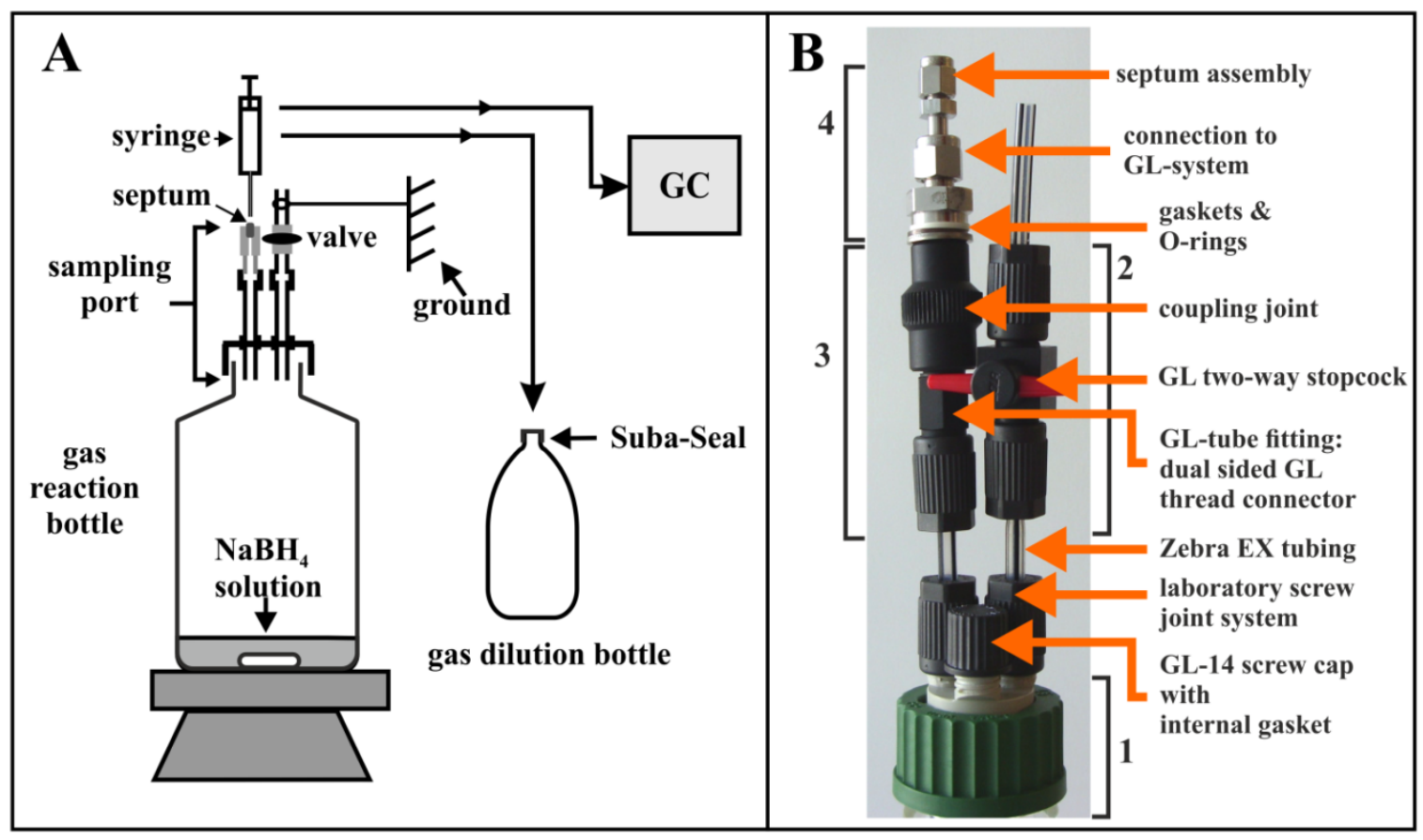

Figure 2. (A) Schematic diagram of the gas-tight bottle assembly used for the production of $\mathrm{H}_{2}$ from defined amounts of $\mathrm{NaBH}_{4}$. Gas sampling was performed by using a home-made sampling port assembly containing a gas-tight septum. In this Figure, a "gas dilution bottle" (sealed with a Suba-Seal ${ }^{\circledR}$ cap) is also shown, which can be used to dilute pressurized gas samples to atmospheric pressure (see Materials and Methods). (B) Details of the gas-tight sampling apparatus: (1) GL-45 cap with 3 GL-14 threaded distributors on its head. The unused port is sealed with a GL-14 screw-cap; (2) an assembly with a connection to an external tubing, which can be used for evacuating the bottle and for flushing the bottle with $\mathrm{N}_{2}$ or other (standard) gas mixtures; (3) the connecting parts between the bottle and (4) the septum assembly containing the gas-tight septum.

For the initiation of the $\mathrm{H}_{2}$-producing reaction, a $\mathrm{NaBH}_{4}$ pellet $\left(0.23 \mathrm{~g} \mathrm{NaBH}_{4}\right.$ pellet (doped with $10 \%(w / w) \mathrm{Co}^{2+}$ catalyst)) was placed in $40 \mathrm{~mL} \mathrm{H}_{2} \mathrm{O}$ in the gas-tight bottle assembly, and the cap closed immediately. According to equation (2), the hydrolysis of $0.23 \mathrm{~g} \mathrm{NaBH}_{4}$ dissolved in excess $\mathrm{H}_{2} \mathrm{O}$ should yield $21.89 \mathrm{mmol} \mathrm{H}_{2}$. This amount of $\mathrm{H}_{2}$ will generate an excess pressure of $0.47 \mathrm{~atm}\left(\right.$ at $20^{\circ} \mathrm{C}$, in the total gas volume of $1.11 \mathrm{~L}$ ), assuming that the reaction goes to completion. The total pressure in the closed bottle is described by Dalton's law:

$$
\text { Air in bottle (before } \mathrm{H}_{2} \text { generation) : } P_{T}=P_{\mathrm{O}_{2}}+P_{\mathrm{CO}_{2}}+P_{\mathrm{N}_{2}}+\sum_{i} P_{i}
$$

Air in bottle $\left(\mathrm{H}_{2}-\right.$ generation initiated $): P_{T}^{H}=P_{\mathrm{O}_{2}}+P_{\mathrm{CO}_{2}}+P_{\mathrm{N}_{2}}+\sum_{i} P_{i}+\boldsymbol{P}_{\mathrm{H}_{2}}$

where $P_{T}$ and $P_{T}^{H}$ are the total pressures in the bottle before and after $\mathrm{H}_{2}$ generation, respectively, and $\mathrm{P}_{\mathrm{O} 2}, \mathrm{P}_{\mathrm{CO} 2}, \mathrm{P}_{\mathrm{N} 2}, \mathrm{P}_{\mathrm{H} 2}$ refer to the partial pressures of the individual gases. $\sum_{i} P_{i}$ reflects the sum of the partial pressures of all other, minor components in air (e.g., argon and other noble gases). 
Now, when a $1.5 \mathrm{~mL}$ sample is extracted from the gas-tight bottle, the gas in the syringe is maintained at the sampling pressure. However, when this sample is injected into the sample loop, the total gas pressure ( $P_{T}^{H}$ in the syringe) is instantly released to atmospheric pressure $\left(P_{T}\right)$, but now the relative partial pressures of the individual gases will be reduced compared to the initial values obtained prior to $\mathrm{H}_{2}$ generation, i.e.,:

$$
P_{T}\left(\text { air }+\mathrm{H}_{2}\right)=P_{\mathrm{O}_{2}}^{\prime}+P_{\mathrm{CO}_{2}}^{\prime}+P_{\mathrm{N}_{2}}^{\prime}+\sum_{i} P_{i}^{\prime}+P_{\mathrm{H}_{2}}^{\prime}
$$

where the $\mathrm{P}_{\mathrm{i}}{ }^{\prime}$ values for $\mathrm{O}_{2}, \mathrm{CO}_{2}$, and $\mathrm{N}_{2}$ are less than their initial values measured prior to $\mathrm{H}_{2}$ generation. Thus, the gases measured at increasing time points after the initiation of $\mathrm{H}_{2}$ generation should show a linear negative correspondence between the $\mathrm{PA}\left(\mathrm{H}_{2}\right)$, due to $\mathrm{H}_{2}$ production, and the $\mathrm{PA}\left(\mathrm{O}_{2}\right)$, due to the suppression of the $\mathrm{P}_{\mathrm{O} 2}$ due to excess $\mathrm{H}_{2}$ partial pressure. A similar decrease of the $\mathrm{CO}_{2}$ PA should also be observed. Figure 3A shows the result of a typical $\mathrm{NaBH}_{4}-\mathrm{H}_{2}$ production experiment, and confirms the expectations (Figure 3B):
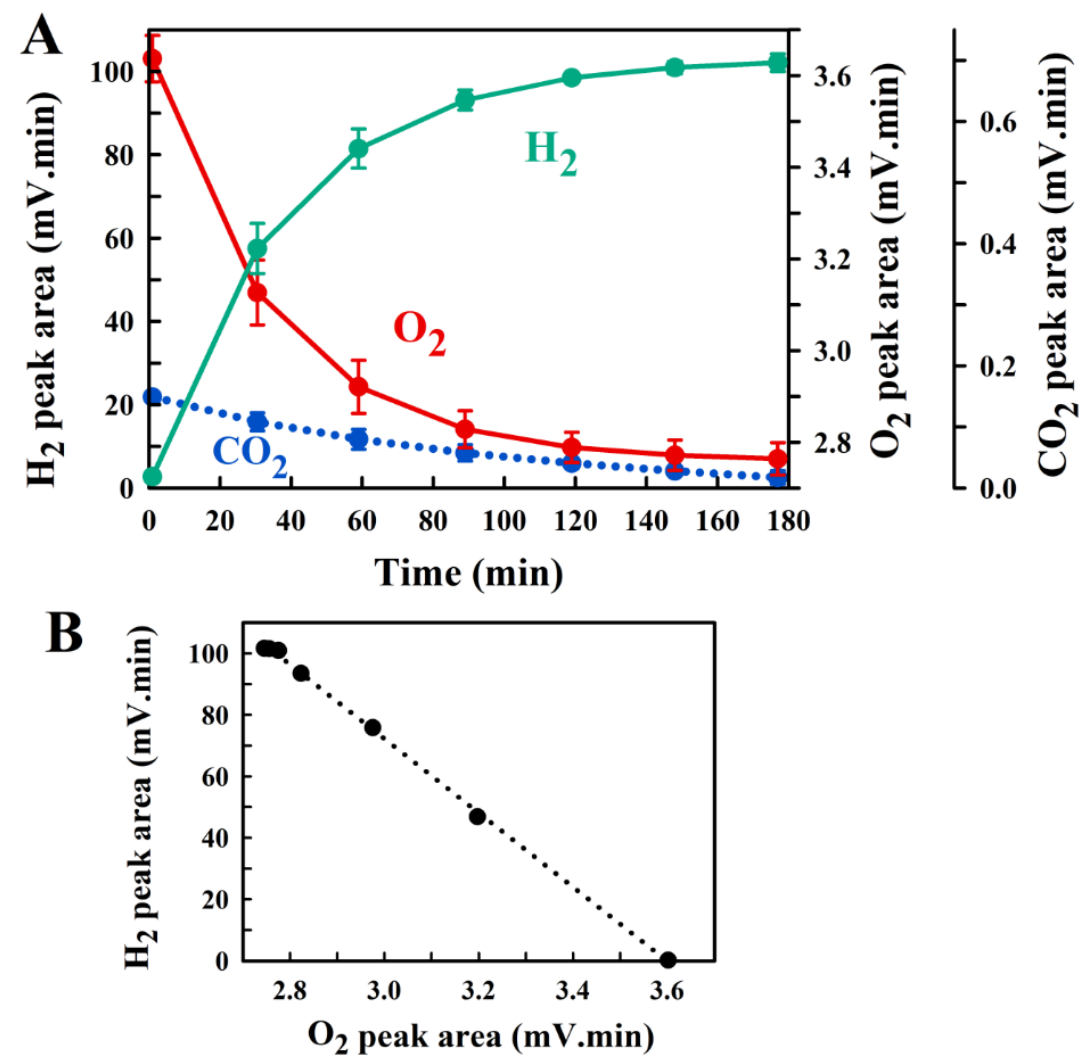

Figure 3. (A) The measured peak areas of the GC-chromatogram obtained in the $\mathrm{NaBH}_{4}-\mathrm{H}_{2}$ evolution experiment. Average values and the respective standard deviations (error bars) from four different experiments are shown. The zero time point refers to the time after addition of the $\mathrm{NaBH}_{4}$ pellet to water. The reaction is essentially complete after $150 \mathrm{~min}$. The plateaus for $\mathrm{H}_{2}$ and $\mathrm{O}_{2}$ confirm the expectation that their reaction at room temperature is negligible for the time of the experiment. In (B) the linear correlation between increase of the $\mathrm{H}_{2}$ peak area and decrease of the $\mathrm{O}_{2}$ peak area is shown.

Using Dalton's law we can show that:

$$
P_{T}^{H}=\gamma P_{T}
$$

where:

$$
\gamma=\frac{P A\left(O_{2}\right)}{P A\left(H_{2}+O_{2}\right)}
$$


where PA $\left(\mathrm{O}_{2}\right)$ and PA $\left(\mathrm{H}_{2}+\mathrm{O}_{2}\right)$ are the peak areas of $\mathrm{O}_{2}$ measured before and after $\mathrm{H}_{2}$ generation, respectively.

Determination of the $\gamma$ value allows the excess pressure $\left(\mathrm{P}_{\mathrm{H} 2}\right)$ due to $\mathrm{H}_{2}$ in the closed bottle to be calculated:

$$
P_{T}^{H}-P_{T}=P_{H_{2}}
$$

After sampling, the high pressure $P_{T}^{H}$ is maintained in the gas-tight syringe. Thus, the number of moles $\mathrm{H}_{2}$ per $1 \mathrm{~mL}$ in the syringe can be calculated by using the ideal gas equation:

$$
n_{H_{2}}=\left(P_{H_{2}} \cdot 1 \mathrm{~mL}\right) /(R T)
$$

After injection into the sample loop, the pressure is released to $P_{T}$ and consequently, the amount of moles $\mathrm{H}_{2}$ in the $1 \mathrm{~mL}$ sample loop is reduced to:

$$
n^{\prime} H_{2}=\gamma^{-1} \cdot n_{H_{2}}
$$

The $\mathrm{H}_{2}$ conversion coefficient is then calculated by dividing $\mathrm{n}_{\mathrm{H} 2}^{\prime}$ by the $\mathrm{H}_{2}$ peak area obtained in the GC run. (See Section 4 for the justification of Equations (6)-(10)).

Four different experiments for determination of the $\mathrm{H}_{2}$ conversion coefficient were performed. During those experiments, in total 17 GC-measurements were made and the peak areas of $\mathrm{H}_{2}$ and $\mathrm{O}_{2}$ obtained, from which the following average $\mathrm{H}_{2}$ conversion coefficient for the GC chromatogram $\mathrm{H}_{2}$ peak area was calculated:

\section{$\mathbf{H}_{2}$ conversion coefficient $=\underline{0.097} \mu \mathrm{mol} \mathrm{H}_{2} / \mathrm{mV} \cdot \min$}

The standard deviation was $0.002 \mu \mathrm{mol} / \mathrm{mV} \cdot \mathrm{min}$, i.e., a $1.8 \%$ error.

\subsubsection{Determination of the GC-Conversion Coefficient for $\mathrm{CO}_{2}$}

Whereas measurements of air are of sufficient accuracy for the determination of the $\mathrm{O}_{2}$ conversion coefficient, the determination of a GC-conversion coefficient for $\mathrm{CO}_{2}$ is not possible with air measurements, since the $\mathrm{CO}_{2}$ peak is small and shows a very high variation from measurement to measurement. In $22 \mathrm{GC}$-measurements of $1.5 \mathrm{~mL}$ air, the $\mathrm{CO}_{2}$ peak varied between $0.0975 \mathrm{mV} \cdot \mathrm{min}$ and $0.3661 \mathrm{mV} \cdot \mathrm{min}$ (average: $0.2187 \mathrm{mV} \cdot \mathrm{min}$, standard deviation: $36.9 \%$ ).

Therefore, a commercially supplied standard $\mathrm{H}_{2} / \mathrm{CO}_{2}$ gas mixture $\left(2\right.$ vol. $\% \mathrm{CO}_{2}$, 6 vol. $\% \mathrm{H}_{2}$, and 92 vol. $\% \mathrm{~N}_{2}$ ) was used for $\mathrm{CO}_{2}$ calibration and to check the $\mathrm{H}_{2}$ conversion coefficient obtained by using the $\mathrm{NaBH}_{4}$-method (see Section 4 for sampling details).

In the event, we observed that the $\mathrm{H}_{2}$ conversion coefficient derived from the $\mathrm{H}_{2} / \mathrm{CO}_{2}$ standard $(0.088 \pm 2.8 \% \mu \mathrm{mol} \mathrm{H} / \mathrm{mV} \cdot \mathrm{min})$ was consistently lower (about $9 \%$ ) than the value calculated from ideal gas laws. However, we were able to show that of the $9 \%$ error, $3 \%$ is contributed by the syringe gas sampling error, which leaves only a $6 \%$ discrepancy between the calculated and measured values. We consider this error to be acceptable for most practical purposes.

The average $\mathrm{CO}_{2}$ conversion coefficient using the standard gas mixture was $0.240 \pm 3.1 \%$ $\mu \mathrm{mol} \mathrm{CO} 2 / \mathrm{mV} \cdot \mathrm{min}$.

\section{$\mathrm{CO}_{2}$ conversion coefficient $=\underline{0.240 \mu \mathrm{mol} \mathrm{CO}} / \mathrm{mV} \cdot \mathbf{m i n}$}

2.2. Experimental Setup for Semi-Aerobic Growth of a $\mathrm{H}_{2}$ Producing Photosynthetic Bacterium, R. Rubrum

In the following, we will describe an application example for the use of the gas-tight components for EX-protection and the determined GC-conversion coefficients described 
above. Usually, for $\mathrm{H}_{2}$-production with photosynthetic microorganisms including algae as well as purple bacteria, the cultures have to be shifted to anaerobic conditions before $\mathrm{H}_{2}$-production can occur [6-11]. In those setups, monitoring the $\mathrm{H}_{2}$-production phase is relatively easy, since $\mathrm{H}_{2}$ is the only variable gas component, and thus, a pressure increase can be correlated to the amount of $\mathrm{H}_{2}$ produced.

In bioreactor setups where organisms are grown in a mixed metabolic regime (usually some combination of anaerobic and aerobic metabolic modes [15,18], see [19] for more examples using different phototrophic bacteria) the profiles of gas evolution and consumption can more complicated.

Here, we demonstrate our method by analysing the gas utilisation and production of the purple photosynthetic bacterium, R. rubrum, under semi-aerobic $\left(\mathrm{O}_{2}\right.$-limited growth, see below for a more detailed discussion of the relevant physiology), "dark photosynthetic" growth conditions. In R. rubrum (as for other photosynthetic organisms) $\mathrm{H}_{2}$ is released when "photosynthetic" anaerobic metabolism produces an excess amount of reducing equivalents, which is the case when fructose or pyruvate are one of the carbon substrates $[18,20]$. We have shown previously that under conditions of semi-aerobic growth $\left(\mathrm{P}_{\mathrm{O} 2}<0.3 \%[18,21]\right)$ in a special culture medium, M2SF medium, that $R$. rubrum will maximally express photosynthetic genes that are normally produced under anaerobic photosynthetic conditions [15]. This growth regime we define as "dark photosynthetic", since all photosynthetic gene regulatory mechanisms are in place, albeit in the absence of light. We note in passing that the semi-aerobic regime (which is determined by the number and amounts of cytochrome oxidases present) is different for other photosynthetic bacteria.Thus, for Rhodobacter capsulatus, the "semi-aerobic" growth regime causing photosynthetic membrane expression, is already observed at $\mathrm{P}_{\mathrm{O} 2}<8 \%$ [22]. The transition from aerobic to "dark photosynthetic" semi-aerobic growth is causal to gene expression of specialized photosynthetic membranes, which are comprised of about $50 \%$ light-harvesting complexes. Since the absorbance at $882 \mathrm{~nm}$ is exclusively due to the light-harvesting complexes, the ratio $A_{882} / A_{660}$ is a diagnostic parameter for the level of photosynthetic membranes/cell. In a typical growth experiment, below cell densities corresponding to an $\mathrm{A}_{660}$ (4 mm path-length) of about 0.2 , the genes required for photosynthesis (which include those for photosynthetic membrane production) are repressed by $\mathrm{O}_{2}$. At high $\mathrm{A}_{660}$ values, the $\mathrm{O}_{2}$ consumption by the cells is so high that the local (liquid phase) $\mathrm{P}_{\mathrm{O} 2}$ falls below $0.3 \%$, and photosynthetic genes are expressed. If aerobic M2SF cultures are inoculated with cells from fully grown semi-aerobic cultures, where the $\mathrm{A}_{882} / \mathrm{A}_{660}$ ratio is high, photosynthetic membrane expression is initially arrested and the $A_{882} / A_{660}$ ratio decreases until the cell density reaches an $\mathrm{A}_{660}(4 \mathrm{~mm})$ of 0.2 , whereupon the $\mathrm{A}_{882} / \mathrm{A}_{660}$ ratio begins to rise. The result is a noticeable trough in the $\mathrm{A}_{882} / \mathrm{A}_{660}$ profile, which indicates the transition to semiaerobic growth. Under normal M2SF growth conditions, the $\mathrm{H}_{2}$-producing nitrogenase is completely repressed by the high levels of ammonia in the medium $[23,24])$, so that $\mathrm{H}_{2}$ can only be produced by the action of the formate-hydrogen lyase $[20,25,26]$, or the reversible hydrogenases [23,27], both of which are reversibly inhibited by $\mathrm{O}_{2}$.

At present, the dynamics of the reciprocal $\mathrm{O}_{2}$ utilisation and $\mathrm{H}_{2}$ production in semiaerobic cultures of R. rubrum growing in M2SF medium have not been characterized. Here we use our method to conduct the first analysis of this effect. However, the difficulty in establishing an experimental design for this purpose is that, within a closed setup, the culture needs to access a large quantity of $\mathrm{O}_{2}$ for proper growth, and the $\mathrm{H}_{2}$ produced has to be collected for further analysis. Thus, in our initial setup (Figure 4), a one litre culture flask containing $524 \mathrm{~mL}$ of a $R$. rubrum culture was connected to two 5 litre bottles, which were used both as $\mathrm{O}_{2}$-reservoir and collection bottles for the $\mathrm{H}_{2}$-gas produced. The gastight setup incorporated switching valves for sampling of liquid and gas samples without modifying the gas composition as well as the sterility of the chamber during measurement. 

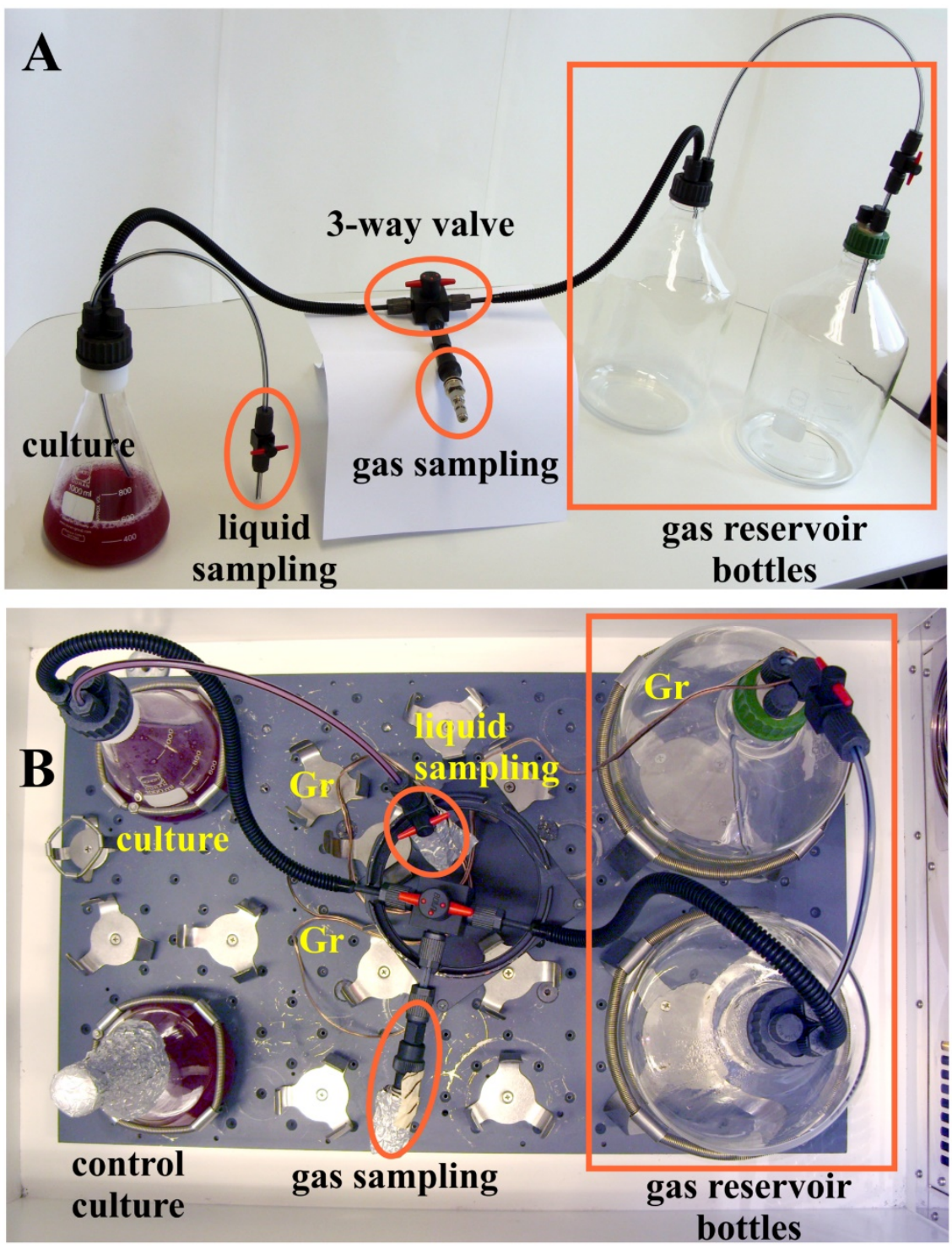

Figure 4. (A) The experimental setup for semi-aerobic incubation of R. rubrum using gas-tight and explosion-proof tubing and connections. (B) shows the positions of the bottles and flasks in the shaker during the growth experiment. The copper wire (Gr) used for grounding is also visible. The control culture (bottom left) is also shown. The growth experiment was performed in the dark (in a closed, light-tight shaker) at $30^{\circ} \mathrm{C}$.

The results of a typical M2SF growth experiment in a $504 \mathrm{~mL}$ culture, using a $20 \mathrm{~mL}$ inoculum, are shown in Figure 5.

The time course of the experiment can be divided into 3 phases (separated by dashed lines in Figure 5), which reflect different physiological modes of the R. rubrum culture. At the start of the experiment, the culture medium is saturated with $\mathrm{O}_{2}$ (in air), and the gas reservoir contains $\mathrm{O}_{2}$ at the normal atmospheric concentration. During the first $14 \mathrm{~h}$ of cell growth, $\mathrm{O}_{2}$ in the medium is rapidly consumed, leading to the establishment of the semi-aerobic growth regime (at a $\mathrm{P}_{\mathrm{O} 2}<0.3$ [21]), which is indicated by the trough in the $\mathrm{A}_{882} / \mathrm{A}_{660}$. At this point, photosynthetic genes are induced (the "dark-photosynthetic" growth regime), reflected by the rise of the $\mathrm{A}_{882} / \mathrm{A}_{660}$ values. $\mathrm{H}_{2}$ accumulation starts approximately $9 \mathrm{~h}$ later (at a gas-phase $\mathrm{P}_{\mathrm{O} 2} \sim 13 \%$ ) and reaches a peak at $63 \mathrm{~h}$, after which the cells enter the stationary phase. In the stationary phase, all the fructose in the medium has been consumed, as indicated by measurements of fructose concentrations in the culture medium supernatant (data not shown). In this last phase, the depletion of cellular reducing 
equivalents can be partially compensated by the uptake of $\mathrm{H}_{2}$, mediated by the reversible $\mathrm{H}_{2}$ ase activity. The apparent rise of $\mathrm{O}_{2}$ after the time point $47 \mathrm{~h}$ is an artefact due to the fact that in the late phase of growth, $\mathrm{H}_{2}$ and $\mathrm{CO}_{2}$ are consumed, which leads to a lower pressure than atmospheric, which is maintained in the gas-tight syringe after sampling. Thus, when the sampled gas is injected into the GC sample loop, air will enter the GC loop, thus (artefactually) raising the effective partial molar volume of the measured gases over their true values in the gas-tight syringe. We note that $R$. rubrum does not produce $\mathrm{O}_{2}$ under any growth conditions. In future works, an external digital manometer may be used to calculate the true gas concentrations for the late growth phase.

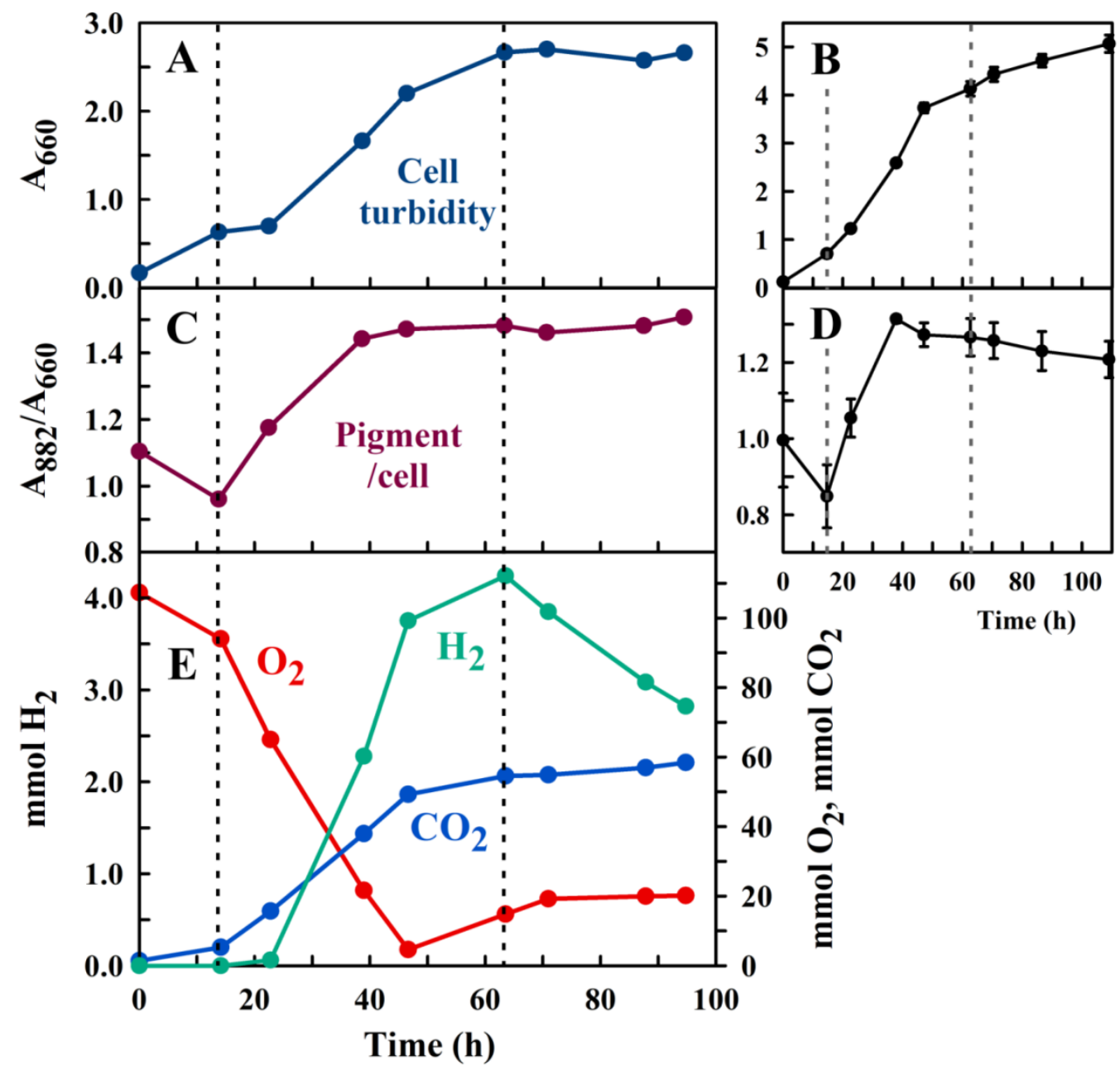

Figure 5. The R. rubrum growth experiment. (A,B) The absorption at $660 \mathrm{~nm}\left(\mathrm{~A}_{660}\right.$, calculated for $1 \mathrm{~cm}$ path-length), reflecting cell growth of a single closed culture during the $\mathrm{H}_{2}$ production experiment $(\mathbf{A})$ and the averaged data of three independent (open) control cultures (B). (C,D) The ratio $\mathrm{A}_{882} / \mathrm{A}_{660}$, reflecting the expression of photosynthetic membranes of a single closed culture (C) and the averaged data of three control cultures (D). The (B,D) panels (which show also the standard deviations of the measurements) have been included to show the reproducibility of the growth experiment. (E) GC measurements of gases in the total 12.5 litre gas reservoir of the closed hydrogen producing culture (see Section 4). The values shown are calculated amounts per litre culture. The first dashed line (at $13.8 \mathrm{~h}$ ) shows the commencement of semi-aerobic growth, the second dashed line (at $63.3 \mathrm{~h}$ ) indicates the establishment of the stationary growth phase (see main text).

The final cell density of the $\mathrm{H}_{2}$-producing closed culture was only approximately half of that which was achieved by the control cultures (Figures 4B and 5B) which had been closed with a standard cotton wool stopper, thereby allowing unhindered gas exchange with the atmosphere. However, the final pigment content $\left(\mathrm{A}_{882} / \mathrm{A}_{660}\right)$ was 1.2-fold higher in the closed setup compared to the control cultures (compare panels in Figure 5C,D). 
Both the lower cell density and higher $\mathrm{A}_{882} / \mathrm{A}_{660}$ of the closed system indicated that this setup was $\mathrm{O}_{2}$-limited when compared with the control cultures. The possibility that the tubing connecting the sampling port to the reaction vessel is too thin to allow efficient gas exchange is unlikely, as separate measurements of gas exchange (using $\mathrm{CO}_{2}$ as a reference gas) showed that equilibration between culture and gas reservoirs occurred well within the time increment (about $12 \mathrm{~h}$ ) of sampling (data not shown). However, since the solubility of $\mathrm{O}_{2}$ in water is relatively low (see [28] for a detailed discussion of $\mathrm{O}_{2}$ availability in microaerobic cultures), the local $\mathrm{O}_{2}$ concentration in the culture dropped below the limit that is needed for optimal growth.

The problem of $\mathrm{O}_{2}$ limitation might be circumvented by leaving the "closed" setup in an "open" state (i.e., freely accessible to air) for the first $24 \mathrm{~h}$ where no significant $\mathrm{H}_{2}-$ production was observed, but where the $\mathrm{A}_{660}$ values of the control and closed culture already started to diverge. Additionally, the gas reservoirs could be exchanged during the experiment and a ventilation system installed inside the gas reservoir bottles, or, alternatively, a third 5 litre reservoir bottle could be connected to the setup. These optimisation possibilities will be studied in future work.

\section{Discussion}

In this work, we have established and calibrated a gas-tight and explosion proof setup for $\mathrm{H}_{2}$-production at the small biological laboratory scale, involving cultures of around $0.5-2$ litres.

The use of $\mathrm{H}_{2}$ produced by the reaction of $\mathrm{NaBH}_{4}$ with $\mathrm{H}_{2} \mathrm{O}$ described in this study, together with the application of ideal gas laws, is an easy and cheap way to calibrate a GC without the use of commercial standard (often pressurized) gas mixtures, and can provide a starting point for more sophisticated experimental studies. In particular, the response of the GC detector from very low to high concentrations of $\mathrm{H}_{2}$ can be deduced in a single experiment. However, since the sampling septum geometry of the $\mathrm{H}_{2}$-generating system may be slightly biased by the accumulation of $\mathrm{H}_{2}$ at the top of the vessel over time, for very precise measurements it is advisable to employ a commercial $\mathrm{H}_{2}-\mathrm{CO}_{2}$ gas standard, to standardize the $\mathrm{H}_{2}$ detector response for a reference $\mathrm{H}_{2}$ concentration.

We are aware of course, that all the aforementioned gases are not strictly ideal in behaviour. However, at the low gas concentrations usually relevant for biological systems, the necessary corrections (employing the known virial coefficients) for real gas behaviour are negligible (see below). We also note that the quantitative effect of increased hydrogen partial pressures upon $\mathrm{H}_{2}$ production in closed vessels has also been considered previously for small (15 mL) closed anaerobic cultures of Chlamydomonas reinhardtii [29].

Throughout the work described here, a special emphasis was laid on the fact, that a self-built (non-technical) setup for biological $\mathrm{H}_{2}$ production still has to fulfill the demand for both gas-tightness (and therefore reliability of the results) and safety for the experimentalist, which is not possible, when silicon tubing is used. Here, we used special conductive plastic parts and metal parts for the assembly of gas-tight setups (see Section 4 and also the Supplementary Material for material sources). Our construction design could also be useful for adaptation to the small technical scale. The constructions shown here are both modular and robust and well-suited to biological work. Also the system does not utilize silicon tubing, which appears to be almost universally employed for small-scale bio- $\mathrm{H}_{2}$ production experiments. In fact, although silicon tubing is cheap, it is not really $\mathrm{H}_{2}$-tight and cannot be grounded, and is therefore highly inferior for bio- $\mathrm{H}_{2}$ experiments.

Finally, we have demonstrated the applicability of the method to a real bio- $\mathrm{H}_{2}$ production experiment, involving the purple photosynthetic bacterium, $R$. rubrum. We showed that the reciprocal dynamics of $\mathrm{O}_{2}$ consumption and $\mathrm{H}_{2}$ production as well as the net behaviour of $\mathrm{CO}_{2}$, under conditions of semi-aerobic growth, can be reliably followed, and are consistent with previous observations [18] and known biological mechanisms of $\mathrm{H}_{2}$ production in R. rubrum. 


\section{Materials and Methods}

\subsection{Chemicals and Materials}

In general, chemicals were obtained from Sigma-Aldrich/Merck (Darmstadt, Germany), Roth (Karlsruhe, Germany), Häberle (Lonsee-Ettlenschieß, Germany), or VWR/Avantor (Darmstadt, Germany) and were of analytical (or higher) grade. Ultrapure water was taken from a Synergy ${ }^{\circledR}$ UV water purification system (Millipore/Merck (Darmstadt, Germany)).

The commercial $\mathrm{H}_{2}$ and $\mathrm{CO}_{2}$ gas standard $\left(6\right.$ vol. $\% \mathrm{H}_{2}, 2$ vol. $\% \mathrm{CO}_{2}, 92$ vol. \% $\mathrm{N}_{2}$; all gases were 5.0 grade, i.e., $99.999 \%$ pure) was obtained pre-mixed and custom-filled in a 1 litre gas cylinder, delivered with an appropriate reducing valve, from Kraiss \& Fritz (Stuttgart, Germany). For sampling the commercial $\mathrm{H}_{2} / \mathrm{CO}_{2}$ gas mixture, a $100 \mathrm{~mL}$ glass bottle was first evacuated for $2 \mathrm{~min}$ (which avoids accumulation of $\mathrm{H}_{2}$ at the top of the assembly) using a membrane vacuum pump, then the bottle was flushed with the standard gas mixture for 1 min using the cap assembly (input tubing assembly (2)) shown in Figure 2B. The evacuating and flushing step was repeated once. Then, a dummy $1.5 \mathrm{~mL}$ sample was taken via the gas-tight septum and discarded. A second $1.5 \mathrm{~mL}$ sample was taken for subsequent measurement in the GC. All measurements were performed in triplicate.

Components required for the construction of the closed setup apparatus used for the $\mathrm{H}_{2}$ production experiments were obtained from Bohlender (Grünsfeld, Germany; product brand: BOLA) and Swagelok (Cleveland, OH, USA). The septum used for gas-tight gas sampling was the Septa Thermolite ${ }^{\circledR}$ Shimadzu Plug from Restek (Bad Homburg, Germany). A complete list of the parts used for building the setup apparatus can be found in Supplementary Figure S1 and Supplementary Table S1.

For tight sealing of glass bottles or vials in the gas-dilution experiments, Suba-Seal ${ }^{\circledR}$ rubber septa (Sigma-Aldrich/Merck (Darmstadt, Germany)) were used.

Glass DURAN ${ }^{\circledR}$ bottles and culture flasks were obtained from Schott (Mainz, Germany).

The $2.5 \mathrm{~mL}$ Luer-lock gas-tight syringe for gas sampling was obtained from SGE Analytical Science/Trajan Scientific and Medical (Ringwood, Victoria, Australia). The needle used (metal hub; gauge: 23; length: $51 \mathrm{~mm}$; point style: 5 (side port to prevent needle clogging)) was from Hamilton Europe (Giarmata, Romania). Since the syringe was not sample-locked, we determined the kinetics of syringe leakage by removing a sample of fixed volume $(1.5 \mathrm{~mL})$ from the sealed $\mathrm{H}_{2}$-producing $\mathrm{NaBH}_{4}$ reaction bottle (see Figure 2), where the $\mathrm{H}_{2}$ level had reached the steady state, and then measuring the sample by gas chromatography after defined syringe waiting times. The loss of gas in the syringe was shown to obey first-order kinetics, allowing us to determine the half-time of gas leakage to be about $140 \mathrm{~min}$. Thus, in the time that is required to take the sample and transfer it to the gas chromatograph loop (less than one minute), we expect a loss of only $0.5 \%$ gas sample. This value falls well within the sampling error.

\subsection{The Gas Chromatograph Protocol}

Gases were quantitated by GC using a Thermo Scientific ${ }^{\mathrm{TM}}$ TRACE ${ }^{\mathrm{TM}} 1300$ gas chromatograph (Thermo Fisher Scientific, Waltham, MA, USA). The stationary phase consisted of two micropacked columns (packing material: ShinCarbon ST; Silcosteel ${ }^{\circledR}$ coated tubing; outer diameter: 1/16 inch; length: $2 \mathrm{~m}$ ), connected in series. $\mathrm{N}_{2}$ gas (grade 5.0) was used as the mobile phase with an effective flow rate of $10.0 \mathrm{~mL} / \mathrm{min}$. Gases were detected using a thermal conductivity detector (TCD), which was maintained at $200{ }^{\circ} \mathrm{C}$ during the GC-run (filament temperature: $330^{\circ} \mathrm{C}$; front detector polarity: negative; reference gas: $\mathrm{N}_{2}$ (5.0 grade, flow rate: $4.0 \mathrm{~mL} / \mathrm{min}$ )). Instrument control and data analysis were performed using the Chromeleon 7.2 software package (Thermo Fisher Scientific, Waltham, MA, USA). Gas samples were injected manually, using a gas-tight syringe and a manual injection port at the GC. The GC run was performed at $35^{\circ} \mathrm{C}$ for the first $6.5 \mathrm{~min}$. Then, a temperature ramp of $10^{\circ} \mathrm{C} / \mathrm{min}$ was started from $35^{\circ} \mathrm{C}$ to $170^{\circ} \mathrm{C}$ until the end of run at $20 \mathrm{~min}$, which was followed by a cooling period to $35^{\circ} \mathrm{C}$ that lasted approximately $5 \mathrm{~min}$. Routinely, one 
or two "dummy" runs with $1.5 \mathrm{~mL}$ air were performed prior to gas measurements in order to eliminate spurious signals due to dirt accumulation.

The relevant peak positions of the gas components (see Figure 1) were assigned using ambient air as a standard for $\mathrm{O}_{2}$ and $\mathrm{CO}_{2}$. The $\mathrm{CO}_{2}$ peak position was confirmed by the measurement of a gas sample taken from the headspace of a bottle filled with soda water. With our GC protocol, $\mathrm{O}_{2}$ and $\mathrm{CO}_{2}$ had a retention time of $3.16 \mathrm{~min}$ and $15.76 \mathrm{~min}$, respectively. The retention time of $\mathrm{H}_{2}$, as determined using $\mathrm{H}_{2}$-containing gas samples, obtained by the reaction of $\mathrm{NaBH}_{4}$ with $\mathrm{H}_{2} \mathrm{O}$, was $1.26 \mathrm{~min}$. An example of a typical GC measurement is shown in Figure 1.

Routinely, the $1 \mathrm{~mL}$ sample loop was overfilled with $1.5 \mathrm{~mL}$ gas sample, to ensure that no ambient gas enters the loop during measurement. In control experiments, where only $1 \mathrm{~mL}$ sample were injected, we observed that about $60 \mu \mathrm{L}$ of ambient air $(6 \%$ of the injected volume) was able to enter the measurement loop, thereby raising the standard variation for the $\mathrm{O}_{2}$ peak area from $1.4 \%$ (overfilled loop) to $2.7 \%$.

The linearity between gas concentration and GC peak area was confirmed by mixing defined volumes of air (which contains 21 vol. $\% \mathrm{O}_{2}$ ) with pure $\mathrm{N}_{2}$ in the gas-tight $2.5 \mathrm{~mL}$ syringe in ratios of 1:0 $\left(21 \mathrm{vol} . \% \mathrm{O}_{2}\right), 2: 1\left(14 \mathrm{vol} . \% \mathrm{O}_{2}\right), 1: 1\left(10.5 \mathrm{vol} . \% \mathrm{O}_{2}\right)$, and $1: 2\left(7\right.$ vol. $\left.\% \mathrm{O}_{2}\right)$, respectively, and subsequently determining the GC peak areas. All measurements were performed in triplicate. To generate samples with very low $\mathrm{O}_{2}$ concentrations (0.5-4 vol. \% $\left.\mathrm{O}_{2}\right)$, a $17 \mathrm{~mL} \mathrm{~N}_{2}$-filled Pyrex tube (sealed with a Suba-Seal ${ }^{\circledR}$ cap) was "spiked" with varying volumes of air, from which $1.5 \mathrm{~mL}$ samples were analyzed by GC. In the event, the peak area was shown to be linear with the $\left[\mathrm{O}_{2}\right]$, although small deviations (probably due to dilution inaccuracies) were observed at the lowest $\left[\mathrm{O}_{2}\right]$.

Considerations for the Effect of Elevated Pressure in Gas Samples upon the GC Measurement of Gas Concentrations

When gas samples of any given pressure are injected into the GC sample loop, they immediately equilibrate to atmospheric pressure. Whereas the relative gas composition in the sample remains unaffected, the absolute molar concentration of gas is reduced relative to the initial pressurized sample. This complicates the interpretation of GC measurements from biological experiments where the samples taken are often at elevated pressure (e.g., for the sampling of only a gas head space of $2-3 \mathrm{~mL}$ present in a $120 \mathrm{~mL}$-culture bottle filled with a photosynthetically growing anaerobic $R$. rubrum culture, from which gas samples are taken).

Attempts to dilute high pressure gas samples with $\mathrm{N}_{2}$ directly in the gas-tight syringe were not successful, since unacceptably large errors occurred. Therefore, for high pressure samples we devised an alternative methodology, in which the gas sample (usually $0.5-1.0 \mathrm{~mL}$ ) was injected into a $260.9 \mathrm{~mL}$ gas dilution bottle (sealed with a Suba-Seal ${ }^{\circledR}$ cap). This approximately 250-fold dilution eliminates the pressure effect, and $1.5 \mathrm{~mL}$ samples taken from the gas dilution bottle for GC-measurement can be regarded as samples at atmospheric pressure.

\subsection{BOLA and Swagelok Components and Connections used for Constructing Gas Sampling Assemblies}

To make gas-tight connections between lab glassware bottles and flasks, a screw joint system is required which connects the thread on the glassware (usually of "GL"-type) with a screw cap containing the tubing. In the commercially available (BOLA) screw joint system described here, three different sealing rings mesh perfectly, so that the cap with the tubing is screwed tightly onto the GL thread. The same screw joint sealing methodology is also used in technical systems (here: Swagelok), in order to connect metal parts with threads to tubes via tube fittings. The threads in technical systems are usually of NPT or ISO type. Screw joints provide much more flexibility in comparison to setups, which were made gas-tight by welding the parts together.

Most of the laboratory screw joint system and other components for EX-protection (e.g., tube-fittings, tubing, and stopcocks) used here were standard BOLA parts (GL-14 
thread size, tubing with $6 \mathrm{~mm}$ outer diameter and $4 \mathrm{~mm}$ inner diameter). The coupling joint, however, containing a GL-14 inner thread and a cylindrical G1/4" inner thread, which connected the plastic BOLA-parts with the metal Swagelok septum assembly (see Figure 2B), was a special model (EX-protected) manufactured for us by Bohlender. Gastightness of the connections was tested by flushing the setup with $\mathrm{N}_{2}$ at high pressure and checking for foam formation by using a commercial tenside formulation (the Snoop ${ }^{\circledR}$ liquid leak detector (Swagelok)) which is commonly used in engineering environments for the detection of very small leaks. Even though the threads were well-fitting, it was difficult to make gas-tight connections between the plastic and the metal parts. Only after fixing this connection with three different gasket rings (from Swagelok), gas-tightness could be achieved. The whole assembly containing the three-gasket connection setup was shown to be vacuum-tight for a period of several days in preliminary growth experiments where only a 1 litre bottle was used as the gas reservoir instead of the two 5 litre bottles used later (Figure 4). In the preliminary experiment, a vacuum developed, which prevented sampling using a gas-tight syringe.

The septum assembly was made of metal Swagelok parts, because the septum used fits perfectly into the $1 / 8^{\prime \prime}$ Swagelok tube fitting at the end of the assembly. This septum assembly was gas-tight, even after autoclaving and several sampling events (all calibration experiments could be performed using the same septum). For the bacterial growth experiments, however, we regularly used a new septum as precaution against septum fatigue during the course of the experiment.

Finally, we note that, whereas the connections of the plastic-type apparatus described above are straightforward, the connections between steel and plastic tubing often require some level of improvisation (e.g., more than one intermediate washer (gasket) at the steel-plastic interface, or attention to the compatibility of "cylindrical" or "conical" screw connections, etc.) in order to achieve a high level of gas-tightness.

\subsection{Calibration of the $\mathrm{H}_{2}$ GC-Signal}

Justification for Equations (6)-(10) in Section 2:

In the closed bottle in the absence of $\mathrm{NaBH}_{4}$-induced $\mathrm{H}_{2}$, we can write the gas pressures with Dalton's law (see Section 2 for symbol definitions):

$$
P_{T} V=\left(P_{\mathrm{O}_{2}}+P_{\mathrm{N}_{2}}+P_{\mathrm{CO}_{2}}+\sum_{i} P_{i}\right) V
$$

which can also be written as:

$$
P_{T}(\text { air })=n_{\boldsymbol{o}_{2}} \frac{R T}{V}+n_{N_{2}} \frac{R T}{V}+n_{\mathrm{CO}_{2}} \frac{R T}{V}+\sum_{i} n_{i} \frac{R T}{V}
$$

In the presence of $\mathrm{NaBH}_{4}$-induced $\mathrm{H}_{2}$, the total pressure increases to $P_{T}^{H}$, and Equation (12) is modified:

$$
P_{T}^{H}\left(\text { air }+H_{2}\right)=n_{H_{2}} \frac{R T}{V}+n_{o_{2}} \frac{R T}{V}+n_{N_{2}} \frac{R T}{V}+n_{\mathrm{CO}_{2}} \frac{R T}{V}+\sum_{i} n_{i} \frac{R T}{V}
$$

If $1 \mathrm{~mL}$ of this gas is filled in the GC sample loop, $P_{T}^{H}$ will once again be reduced to $\mathrm{P}_{\mathrm{T}}$ by a factor $\gamma$ :

$$
P_{T}\left(a i r+H_{2}\right)=\gamma^{-1} P_{T}^{H}=\frac{R T}{V}\left(\gamma^{-1} n_{H_{2}}+\gamma^{-1} n_{O_{2}}+\gamma^{-1} n_{N_{2}}+\gamma^{-1} n_{C O_{2}}+\gamma^{-1} \sum_{i} n_{i}\right)
$$

or

$$
P_{T}\left(\text { air }+H_{2}\right)=\gamma^{-1} P_{T}^{H}=\frac{R T}{V}\left(n^{\prime} H_{2}+n^{\prime} O_{2}+n{ }_{N_{2}}+n{ }^{\prime} \mathrm{CO}_{2}+\sum_{i} n_{i}{ }^{\prime}\right)
$$

Note that our formalism uses only the ideal gas equation and does not require corrections for real gases. The rationale for this assumption is that only ambient or near ambient 
pressures are relevant in most physiological experiments. For mesobaric organisms, excess pressures above about $1.5 \mathrm{~atm}$ are severely inhibitory for growth, so that the real gas corrections are essentially negligible. We illustrate this using a simple calculation. Considering only oxygen, the deviation from ideal gas behaviour can be described using the virial equation [30]:

$$
P V_{m}=R T\left(1+\frac{B}{V_{m}}+\frac{C}{V_{m}^{2}}+\frac{D}{V_{m}^{3}}+\ldots\right)
$$

where $\mathrm{V}_{\mathrm{m}}$ is the molar volume of the gas component and the constants in parentheses $(1$, B, C, etc.) are the so-called virial coefficients. At near-ambient pressures, only the second virial coefficient, B, is numerically significant, so that Equation (16) simplifies to:

$$
P V_{m}=R T\left(1+\frac{B}{V_{m}}\right)
$$

Thus, the deviation from ideal gas behaviour is given by the deviation in parentheses. For oxygen, $\mathrm{V}_{\mathrm{m}}$ at $298.15 \mathrm{~K}\left(25^{\circ} \mathrm{C}\right)$ and $1 \mathrm{~atm}$ pressure is $24,465 \mathrm{~cm}^{3} \cdot \mathrm{mol}^{-1}$, and $\mathrm{B}$ (at $298.15 \mathrm{~K})$ is $-16.4118 \mathrm{~cm}^{3} \cdot \mathrm{mol}^{-1}$ [30]. Thus, the value of $\mathrm{B} / \mathrm{V}_{\mathrm{m}}$ is $6.7 \times 10^{-4}$, which corresponds to a $-0.07 \%$ deviation from the ideal gas equation. For $\mathrm{N}_{2}$ and $\mathrm{H}_{2}$, the equivalent deviations from the ideal gas equation are also very small (about $-0.022 \%$, and $+0.05 \%$, respectively). For $\mathrm{CO}_{2}$, where $\mathrm{B}$ is significantly larger $\left(-124 \mathrm{~cm}^{3} \cdot \mathrm{mol}^{-1}\right)$ than for the aforementioned gases, the deviation from ideal gas behaviour corresponds to about $0.5 \%$, which is still well within the experimental accuracy of sample measurement (about 5\%). Thus, the assumption of ideal gas behaviour is sufficiently accurate for most conditions in a physiological context.

\subsection{Bacterial Strain, Growth Conditions, and Spectroscopic and Biochemical Analysis of Growth Parameters}

The R. rubrum wild-type strain S1 [31] was used for the growth experiments. Semiaerobic $\left(\mathrm{P}_{\mathrm{O} 2}<0.3 \%[21]\right)$, dark cultivation of the pre-culture was performed in a $250 \mathrm{~mL}$ baffled Erlenmeyer flask in a final volume of $100 \mathrm{~mL}$ modified Sistrom medium, M2S [32,33]. For the $\mathrm{H}_{2}$-production experiment described here, cells were cultivated in a 1 litre Erlenmeyer flask containing 504 mL M2SF medium, which contains higher concentrations of succinate $(40 \mathrm{mM})$ and fructose $(16.7 \mathrm{mM})$ to enhance the expression of photosynthetic genes, as described $[15,21]$. The experiment was initiated by inoculating the M2SF culture medium with $20 \mathrm{~mL}$ of fully grown $R$. rubrum cells (under dim green light), and after closing the gas-tight access to the flask, commencing incubation in a shaker held in the dark at $30{ }^{\circ} \mathrm{C}$. Flasks were shaken at $150 \mathrm{rpm}$ (2.5 cm throw; Model G25 Incubator Shaker, New Brunswick Scientific Co. Inc., Edison, NJ, USA).

For absorption measurements and fructose determinations during the growth curve, $2 \mathrm{~mL}$ samples were taken, twice a day, with a sterile plastic syringe via the liquid sampling tube (see Figure 4). Before sampling, approximately $5 \mathrm{~mL}$ of the culture, residing inside the tube, were taken and discarded. The absorption at $660 \mathrm{~nm}$ and $882 \mathrm{~nm}$ of the culture was measured in $1 \mathrm{~mL}$ plastic cuvettes ( $4 \mathrm{~mm}$ path-length) with a LKB-Pharmacia photometer. Sampling was performed under dim green light.

For fructose determination, at each time point, $1 \mathrm{~mL}$ of culture was pelleted by centrifuging for $2 \mathrm{~min}$ at 14,000 rpm $(11,000 \times g)$, at room temperature, and the medium supernatant stored at $-20^{\circ} \mathrm{C}$ until required for the determination of fructose. To remove proteins from the medium supernatant, $250 \mu$ medium supernatant were precipitated with $17 \mu \mathrm{L}$ of a $72 \%(w / v)$ trichloroacetic acid solution (TCA: final concentration: $4.6 \%(w / v))$, incubated for $30 \mathrm{~min}$ at room temperature, and the protein pellet removed by a $20 \mathrm{~min}$ centrifugation step $(11,000 \times g)$. The fructose content in $10 \mu \mathrm{L}$ to $20 \mu \mathrm{L}$ aliquots of the deproteinized supernatant was determined by performing the modified Kulka method as described in detail by Shaw and Ghosh [34].

The concentrations of gases in the total 12.5 litre gas reservoir of the closed hydrogen producing $(524 \mathrm{~mL})$ culture were determined by sampling $1.5 \mathrm{~mL}$ with a gas-tight syringe 
using the sampling port, with subsequent measurement by GC. The molar concentrations were calculated using the GC-conversion coefficients described above. The total sampling volume (sum of all 9 measurements) corresponds to only $0.1 \%$ of the total reservoir gas volume, which we consider to be negligible.

\section{Conclusions}

The modular construction system described for performing bio- $\mathrm{H}_{2}$ production experiments at the small laboratory scale enables precise gas measurements with a high level of safety. Our protocol for calculating gas concentrations directly from GC measurements is sufficient for many studies, and largely obviates the need for expensive standard pressurized gas mixtures for use as standards. Using this apparatus, we demonstrated that gas production (in particular, $\mathrm{H}_{2}$ production) and gas consumption of the purple photosynthetic bacterium, $R$. rubrum, during "dark-photosynthetic" semi-aerobic growth, can be analysed. The methodology described can easily be extended to other systems where gas metabolism is an issue.

Supplementary Materials: The following are available online at https:/ /www.mdpi.com/article/10 $.3390 /$ metabo11100667/s1, Figure S1: The gas-tight bottle experimental setups used in this study, Table S1: Part-list.

Author Contributions: C.A. and R.G. conceived and designed the experiments; C.A. and S.S. performed the experiments and analyzed the data; C.A. and R.G. wrote the paper. All authors have read and agreed to the published version of the manuscript.

Funding: This research was funded by the Federal Ministry of Education and Research (BMBF grant no. 031B0135), the Vector Stiftung (grant no. P2015-0059), and the Federal Ministry for Economic Affairs and Energy (BMWi grant no. 03EI5407A).

Institutional Review Board Statement: Not applicable.

Informed Consent Statement: Not applicable.

Data Availability Statement: No new data were created or analyzed in this study. Data sharing is not applicable to this article.

Acknowledgments: We thank Gerasimoula Gerasimidou for expert technical assistance. We thank Torsten Boldt, Rainer Mertz, and Jörg Starflinger (Institute of Nuclear Technology and Energy Systems, University of Stuttgart) for discussions and instructions about $\mathrm{H}_{2}$-tightness and -safety. The Swagelok assembly for the septum was built by T. Boldt as part of a technical setup, which will be described in detail elsewhere.

Conflicts of Interest: The authors declare no conflict of interest. The funders had no role in the design of the study; in the collection, analyses, or interpretation of data; in the writing of the manuscript, or in the decision to publish the results.

\section{References}

1. Kruse, O.; Hankamer, B. Microalgal hydrogen production. Curr. Opin. Biotech. 2010, 21, 238-243. [CrossRef]

2. McKinlay, J.B.; Harwood, C.S. Photobiological production of hydrogen gas as a biofuel. Curr. Opin. Biotech. 2010, 21, $244-251$. [CrossRef]

3. Mahidhara, G.; Burrow, H.; Sasikala, C.; Ramana, C.V. Biological hydrogen production: Molecular and electrolytic perspectives. World J. Microb. Biotechnol. 2019, 35, 116. [CrossRef]

4. Eroglu, E.; Melis, A. Microalgal hydrogen production. Int. J. Hydrog. Energy 2016, 41, 12772-12798. [CrossRef]

5. Hassan, A.H.S.; Mietzel, T.; Brunstermann, R.; Schmuck, S.; Schoth, J.; Küppers, M.; Widmann, R. Fermentative hydrogen production from low-value substrates. World J. Microb. Biotechnol. 2018, 34, 176. [CrossRef] [PubMed]

6. Voelskow, H.; Schön, G. $\mathrm{H}_{2}$ production of Rhodospirillum rubrum during adaptation to anaerobic dark conditions. Arch. Microbiol. 1980, 125, 245-249. [CrossRef]

7. Zurrer, H.; Bachofen, R. Aspects of growth and hydrogen production of the photosynthetic bacterium Rhodospirillum rubrum in continuous cultures. Biomass 1982, 2, 165-174. [CrossRef]

8. Ghirardi, M.L.; Togasaki, R.K.; Seibert, M. Oxygen sensitivity of algal $\mathrm{H}_{2}$ - production. Appl. Biochem. Biotechnol. 1997, 63, 141-151. [CrossRef] 
9. Melis, A.; Zhang, L.P.; Forestier, M.; Ghirardi, M.L.; Seibert, M. Sustained photobiological hydrogen gas production upon reversible inactivation of oxygen evolution in the green alga Chlamydomonas reinhardtii. Plant Physiol. 2000, 122, 127-135. [CrossRef] [PubMed]

10. Kim, E.J.; Lee, M.K.; Kim, M.S.; Lee, J.K. Molecular hydrogen production by nitrogenase of Rhodobacter sphaeroides and by Fe-only hydrogenase of Rhodospirillum rubrum. Int. J. Hydrog. Energy 2008, 33, 1516-1521. [CrossRef]

11. Hemschemeier, A.; Melis, A.; Happe, T. Analytical approaches to photobiological hydrogen production in unicellular green algae of Chlamydomonas reinhardtii. Photosynth. Res. 2009, 102, 523-540. [CrossRef]

12. Bandyopadhyay, A.; Stöckel, J.; Min, H.; Sherman, L.A.; Pakrasi, H.B. High rates of photobiological $\mathrm{H}_{2}$ production by a cyanobacterium under aerobic conditions. Nat. Commun. 2010, 1, 1-7. [CrossRef]

13. Carrillo-Reyes, J.; Buitrón, G.; Moreno-Andrade, I.; Tapia-Rodríguez, A.C.; Palomo-Briones, R.; Razo-Flores, E.; Aguilar-Juárez, O.; Arreola-Vargas, J.; Bernet, N.; Braga, A.F.M.; et al. Standardized protocol for determination of biohydrogen potential. MethodsX 2020, 7, 100754. [CrossRef]

14. Bosagh, F.; Rostami, K. A review of measurement methods of biological hydrogen. Int. J. Hydrog. Energy 2020, 45, 24424-24452. [CrossRef]

15. Ghosh, R.; Hardmeyer, A.; Thoenen, I.; Bachofen, R. Optimization of the Sistrom culture medium for large-scale batch cultivation of Rhodospirillum rubrum under semi-aerobic conditions with maximal yield of photosynthetic membranes. Appl. Environ. Microbiol. 1994, 60, 1698-1700. [CrossRef]

16. Bartkus, T.P.; T'ien, J.S.; Sung, C.-J. A semi-global reaction rate model based on experimental data for the self-hydrolysis kinetics of aqueous sodium borohydride. Int. J. Hydrog. Energy 2013, 38, 4024-4033. [CrossRef]

17. Brack, P.; Dann, S.E.; Upul Wijayantha, K.G. Heterogeneous and homogeneous catalysts for hydrogen generation by hydrolysis of aqueous sodium borohydride $\left(\mathrm{NaBH}_{4}\right)$ solutions. Energy Sci. Eng. 2015, 3, 174-188. Available online: https:/ / www.scipedia com/public/Brack_et_al_2015b (accessed on 28 September 2021). [CrossRef]

18. Carius, L.; Hädicke, O.; Grammel, H. Stepwise reduction of the culture redox potential allows analysis of microaerobic metabolism and photosynthetic membrane synthesis in Rhodospirillum rubrum. Biotechnol. Bioeng. 2013, 110, 573-585. [CrossRef] [PubMed]

19. Alloul, A.; Muys, M.; Hertoghs, N.; Kerckhof, F.-M.; Vlaeminck, S.E. Cocultivating aerobic heterotrophs and purple bacteria for microbial protein in sequential photo- and chemotrophic reactors. Bioresour. Technol. 2021, 319, 124192. [CrossRef] [PubMed]

20. Selao, T.T.; Edgren, T.; Wang, H.; Norén, A.; Nordlund, S. Effect of pyruvate on the metabolic regulation of nitrogenase activity in Rhodospirillum rubrum in darkness. Microbiology 2011, 157, 1834-1840. [CrossRef]

21. Grammel, H.; Gilles, E.D.; Ghosh, R. Microaerophilic cooperation of reductive and oxidative pathways allows maximal photosynthetic membrane biosynthesis in Rhodospirillum rubrum. Appl. Environ. Microbiol. 2003, 69, 6577-6586. [CrossRef] [PubMed]

22. Abo-Hashesh, M.; Hallenbeck, P.C. Microaerobic dark fermentative hydrogen production by the photosynthetic bacterium, Rhodobacter capsulatus JP91. Int. J. Low Carbon Technol. 2012, 7, 97-103. [CrossRef]

23. Ormerod, J.G.; Gest, H. Symposium on metabolism of inorganic compounds IV-Hydrogen photosynthesis and alternative metabolic pathways in photosynthetic bacteria. Bacteriol. Rev. 1962, 26, 51-66. [CrossRef] [PubMed]

24. Kanemoto, R.H.; Ludden, P.W. Effect of ammonia, darkness, and phenazine methosulfate on whole-cell nitrogenase activity and Fe protein modification in Rhodospirillum rubrum. J. Bacteriol. 1984, 158, 713-720. [CrossRef] [PubMed]

25. Schön, G.; Voelskow, H. Pyruvate fermentation in Rhodospirillum rubrum and after transfer from aerobic to anaerobic conditions in the dark. Arch. Microbiol. 1976, 107, 87-92. [CrossRef] [PubMed]

26. Gorrell, T.E.; Uffen, R.L. Fermentative metabolism of pyruvate by Rhodospirillum rubrum after anaerobic growth in darkness. J. Bacteriol. 1977, 131, 533-543. [CrossRef]

27. Adams, M.W.W.; Hall, D.O. Isolation of the membrane-bound hydrogenase from Rhodospirillum rubrum. Biochem. Biophys. Res. Commun. 1977, 77, 730-737. [CrossRef]

28. Khoshnevisan, B.; Tsapekos, P.; Alfaro, N.; Díaz, I.; Fdz-Polanco, M.; Rafiee, S.; Angelidaki, I. A review on prospects and challenges of biological H2S removal from biogas with focus on biotrickling filtration and microaerobic desulfurization. Biofuel Res. J. 2017, 16, 741-750. [CrossRef]

29. Kosourov, S.N.; Batyrova, K.A.; Petushkova, E.P.; Tsygankov, A.A.; Ghirardi, M.L.; Seibert, M. Maximizing the hydrogen photoproduction yields in Chlamydomonas reinhardtii cultures: The effect of the $\mathrm{H}_{2}$ partial pressure. Int. J. Hydrogen Energy 2012, 37, 8850-8858. [CrossRef]

30. Atkins, P.W.; De Paula, J.; Keeler, J. Atkins' Physical Chemistry, 11th ed.; Oxford University Press: Oxford, UK, 2018.

31. Cohen-Bazire, G.; Sistrom, W.R.; Stanier, R.Y. Kinetic studies of pigment synthesis by non-sulfur purple bacteria. J. Cell Comp. Physiol. 1956, 49, 25-68. [CrossRef]

32. Sistrom, W.R. A requirement for sodium in the growth of Rhodopseudomonas sphaeroides. J. Gen. Microbiol. 1960, 22, 778-785. [CrossRef] [PubMed]

33. Lupo, D.; Ghosh, R. The reaction center H subunit is not required for high levels of light-harvesting complex 1 in Rhodospirillum rubrum mutants. J. Bacteriol. 2004, 186, 5585-5595. [CrossRef] [PubMed]

34. Shaw, S.; Ghosh, R. A modified Kulka micromethod for the rapid and safe analysis of fructose and 1-deoxy-D-xylulose-5phosphate. Metabolites 2018, 8, 77. [CrossRef] [PubMed] 